\title{
Deciphering landscape preferences: Investigating the roles of familiarity and biome types
}

\author{
Giancarlo Mangone ${ }^{12}$, Raelyne L. Dopko ${ }^{2}, \&$ John M. Zelenski²
}

${ }^{1}$ Symbiosis: Sustainable Design \& Consulting

${ }^{2}$ Department of Psychology, Carleton University, Ottawa, Canada

A copyedited version of this paper appears as:

Mangone, G., Dopko, R. L., \& Zelenski, J. M. (2021). Deciphering landscape preferences: Investigating the roles of familiarity and biome types. Landscape and Urban Planning, 214, 104189. https://doi.org/10.1016/j.landurbplan.2021.104189

Correspondence concerning this article should be addressed to John M. Zelenski, Department of Psychology, Carleton University, 1125 Colonel By Dr, Ottawa, ON K1S 5B6, Canada. Email: john.zelenski@,carleton.ca 


\begin{abstract}
Although people generally have positive evaluations of natural environments and stimuli, theory and research suggest that certain biomes are more preferable than others. Existing theories often draw on evolutionary ideas and people's familiarity with biome types, with familiarity being the most supported, albeit not conclusively, in existing research. Across three samples $(n=720)$ we sought to compare preference ratings of 40 images that represented ten biomes (beach, lake, tropical and temperate forest, marsh, swamp, meadow, park, mountain, and river). We addressed objective familiarity by recruiting samples from two distinct geographies (Florida and Ontario), and we assessed subjective familiarity via image ratings. Familiarity was positively associated with liking biomes, though this trend was stronger for subjective familiarity compared to geography. Substantial variation in biome type preferences could not be attributed to familiarity. Specific biome types were strongly preferred irrespective of familiarity and geography. e.g., beaches and lakes were highly preferred, while marshes and swamps were substantially less preferred than other biome types. Further analyses found that the individual difference of nature relatedness predicted both familiarity and liking of all biomes except beaches, and that there was a lack of seasonal effects (fall and winter) across two Ontario samples. We discuss how results provide qualified support for the familiarity view, limits of this interpretation, how methodological choices such as the number of ratings might impact findings, and the potential applications of these results in landscape design.
\end{abstract}




\section{Deciphering landscape preferences: Investigating the roles of familiarity and biome types}

\section{Introduction}

Evidence from a broad range of studies suggest that natural environments positively impact well—being, from mental restoration research (eg., Korpela et al., 2010; Staats et al., 2003), to worker performance (eg., Knight \& Haslam, 2010; Mangone et al., 2017), to child cognitive, physical, and social development (eg., Laaksoharju et al., 2012), to research on recreation activities and environments (eg., Boyd et al., 2018), to the impacts of forest bathing (eg., Park et al., 2011). Results from these diverse research domains suggest that the benefits conferred to visitors is partially impacted by the type of natural environment visited. To that end, the types of natural environments people visit, and their rate of visiting natural environments is impacted by their ease of accessibility and natural environment type preferences (eg., Boyd et al., 2018; Žlender \& Ward Thompson, 2017). Diverse factors have been found to influence people's relative natural environment type preferences. There is evidence that natural environment type preferences may be influenced by the natural environments that humans evolved with over millenia (eg., Appleton, 1975), by the natural environments they most often visit (eg., Lyons, 1983), by the types that are the most mentally restorative (eg., White et al., 2013), by natural environments that are perceived to confer the most pleasure and stimulation (eg., Hull \& Harvey, 1989), and by the types that are most conducive to the visitor's desired activity (eg., Mangone et al., 2017). However, the relative influence of these (and potentially other) factors, on people's natural environment type preferences has yet to be determined conclusively. This lack of clarity is due to knowledge gaps, methodology issues, and contradictions within existing research. For instance, most natural environment type preference studies evaluate a relatively narrow range of natural environment types, eg five to seven biome types, and do not evaluate major, common 
natural environment type differentiations within individual biome types (sub-biome types), e.g., terrestrial biome types with and without water bodies, diversity of plant species and structure types, etc) (eg., Han, 2007). Yet when less commonly tested biomes and sub-biome types are evaluated, the results often challenge some of the existing preference driver theories, and demonstrate natural environment preferences are more complex than existing theories suggest, eg. general preference for beaches and mountains, and variable preferences of mountain subbiome types: mountains integrated with lakes, forests, waterfalls, and creeks (eg., Hartmann \& Apaolaza-Ibáñez, 2010; Wyles et al., 2017).

In this paper, we aim to reduce some of these knowledge gaps and contradictions, by strategically using novel study design features to evaluate several gaps in a more comprehensive manner than most existing studies. Specifically, we investigate the influence of familiarity and breadth of natural environment types, as well as seasonality, on people's natural environment type preferences. This is accomplished by comparing a relatively wide variety of natural environment types in a single study (10), and strategically drawing samples from two distinct geographies (objective familiarities) and across two seasons. We also explore the individual difference of nature relatedness (subjective connection with nature) in predicting evaluations of these various environments.

\subsection{Evaluation of identified natural environment type preference drivers}

Diverse natural environment type preference theories, hypotheses, and drivers have been proposed and studied. The most cited explanatory theories and hypotheses in the existing literature are based on evolution and familiarity. The innate-evolutionary preference hypothesis suggests that people have an innate, evolution based preference for biome types they evolved with over millions of years, and then develop preferences for other biome types during their 
lifetime based on their interactions (familiarity) with different natural environments (Balling \& Falk, 1982). Savannahs and forests have been proposed to be evolutionary preference driven biome types. Savanna preference theory postulates that because humans lived in savannahs over millions of years, and learned that open, flat spaces with few, isolated trees are relatively secure to view incoming threats, people prefer savannahs (Appleton, 1975). In contrast, the forest evolutionary hypothesis proposes that people evolved more in woodlands, which are dense, tree filled environments (Han, 2007). Woodlands are more difficult to view incoming threats, but similar to savannahs, the canopies offer places to hide. The familiarity preference hypothesis proposes that people prefer biome types that they are accustomed to through personal experience (Lyons, 1983).

There are also several less studied potential preference drivers. There is evidence that restorative environments are relatively highly preferred, compared to less restorative environments (eg., Purcell et al., 2001; Staats et al., 2003; Tenngart Ivarsson \& Hagerhall, 2008; White et al., 2010). Restorative environments promote restoration, the process of restoring physical, psychological, and social capacities (Terry Hartig \& Staats, 2006). There are generally two theories that have driven existing research on restorative environments. Stress Reduction Theory (SRT) emphasizes restorative environments' potential to foster recovery from physchophysiological stress (Ulrich, 1983), while Attention Restoration Theory (ART) emphasizes restorative environments' potential to foster recovery of cognitive capacities from mental fatigue (S. Kaplan, 1995). Both theories are evaluated by subjective feelings of restoration, commonly via The Perceived Restorativeness Scale (PRS) measurement tool (T. Hartig et al., 1997). 
However, the majority of existing preference and restoration studies have not evaluated both preference and restorativeness, and those that do tend to comparatively evaluate one or two natural environment types (often deciduous forest) and urban environment types, rather than comparing diverse natural environment types (eg., Bagot et al., 2015; Purcell et al., 2001; Staats et al., 2003). Nevertheless, there are several more expansive studies that offer some insights. For instance, White (2010) evaluated the perceived restorativeness and preferences for a broad range of built and natural environments categorized across an aquatic-green-built environment type spectrum. Perceived restorativeness increased as preference ratings increased, with environments containing water more preferred than those without. Peron et al., (2002) evaluated the preference, PRS score, and familiarity of seven types of natural environments, mixed naturalbuilt environments, and built environments. Familiar natural environment types were highly rated for restoration and preference, while unfamiliar natural environment types (arctic, prairie, savannah, desert, tropical forest) had relatively lower preference and restorative ratings. These results suggest that unfamiliar natural environments tend to be less preferred. However, each environment type was only represented by a single image, leading Peron et al., (2002) to caution that further research with multiple images per environment type are necessary to evaluate the relationship between environment type, familiarity, preference, and restorativeness. There is considerable evidence from a diverse range of research domains that indicate that natural environments are more restorative and preferred than cultivated parks, eg. ornamental gardens, sports fields, and mowed grass dominated parks and lawns (Bagot et al., 2015; Burgess et al., 1988; Grahn, 1991; Laaksoharju \& Rappe, 2017; Lin et al., 2014; Southon et al., 2017; Tenngart Ivarsson \& Hagerhall, 2008; Tyrväinen et al., 2007; White et al., 2013; Wyles et al., 2017; Žlender \& Ward Thompson, 2017). However, the relative restorativeness and preference for 
various natural environment types doesn't always increase as their relative biodiversity and wildness/naturalness increases. Several natural environment types that are perceived as wild yet relatively low biodiversity are typically highly preferred (eg., beaches and mountains), often moreso than more biodiverse natural environment types, as discussed in Section 1.2. These low biodiversity natural environment types tend to also be perceived as highly restorative, such as in nationwide studies in the UK that found natural environments, particularly coastal environments, forests, and mountains/hills were substantially more restorative than urban parks (Wyles 2017, White 2013). Not all biodiversity may be equal, or positive, in terms of restorativeness and preferences. For instance, 'scraggly' or 'messy' underbrush in forests and meadows are a recurrent negative influence on restorativeness and preferences (eg., Burgess et al., 1988; Martens et al., 2011). The limited quantum of existing studies on these issues, and the methodology issues cited by Peron et al.,(2002), etc., demonstrate the need for further study, particularly of diverse natural environment types.

In addition, there is evidence that individual differences in people's nature relatedness (i.e., sense of subjective connection with nature, broadly) is associated with their preferences. Lyons (1983) found that people's preferences for biome types were higher for those that spent the most time in nature, and less for those that spent less time in nature. Wyles (2017) found more wild biome types were perceived by participants to result in greater momentary nature relatedness and restoration than urban landscapes. Lin et al. (2014) compared availability (i.e., distance to green spaces) with trait nature relatedness and found that the trait was more predictive of spending time in local parks. Although individual difference measures are rare in the natural environment preference literature, nature relatedness may account for additional 
variation in familiarity and liking of natural environments. Moreover, we do not know if this varies across different natural environment types.

While evolution based preferences have been studied considerably more, a number of issues with evolution based preference drivers have been raised by researchers. There are a number of methodological issues with evolution-based preference studies, as discussed in Section 1.2. There is also growing evidence that humans evolved in a more diverse range of biome types and geographic regions than previously considered (eg., Scardia et al., 2019; Townsend \& Barton, 2018). Multiple natural environment types prevalent from an evolutionary context have substantial differences in their relative preference to each other and nonevolutionary prevalent natural environment types in existing studies, and conflicting relative preferences for these natural environment types are found in different studies (eg., mountains, beach, tundra, and coniferous, deciduous and tropical forests most preferred and more preferred than savannahs and cultivated urban tree parks in various studies). This makes it difficult to explain variances in preferences between different natural environment types by their evolution relatedness. Moreover, Townsend \& Barton (2018) provide evidence that trees, not biome types, may be the primary evolutionary driver of natural environment preferences, mainly due to their safety provisions. Townsend and others caution that researchers have incorrectly used evidence that people prefer trees due to an evolutionary based need for safety as the foundation for biome scale environment type preference theories, such as savannah preference theory. Yet a number of biome types that lack trees (eg., beaches, mountains) have been more preferred than tree dominant biome types in a number of studies, as discussed in Section 1.2. This suggests more factors than tree presence influences people's environment type preferences, which may make sense from the evolutionary adaptivity preference perspective. Modern humans use of natural 
environments has shifted more to social activities, since constructed homes and communities have replaced trees for shelter needs, and prepared food has largely obviated the use of trees for hunting. Indeed, there is substantial evidence that the evolutionary development of humans is adaptable, particularly between individuals, and has been strongly impacted by interactions with one's environment rather than genetic inheritance of natural environment type preferences. Moreover, there is evidence that over time the influence of environments on human evolution impacts their environment preferences based on which environments are best for their evolved adaptations and needs (Barrett, 2012).

Collectively these critiques and gaps suggest that prominent evolution-based accounts (e.g., savannah or forest theories) do not fully explain preference drivers. There are also alternative preference drivers that do not rely on evolution to explain people's preferences for different natural environments, and are supported by existing studies.

Overall, we find considerably more evidence supporting familiarity over standard evolution based preference drivers in existing studies (Balling \& Falk, 1982; Echeverri et al., 2017; Hammitt, 1980; Hartmann \& Apaolaza-Ibáñez, 2010; Herzog et al., 2000; Kaplan \& Herbert, 1987; Lyons, 1983). A positive relationship between familiarity and preference has been observed (e.g. Hammit 1980), and several studies have found them to be highly correlated (Balling \& Falk, 1982; Echeverri et al., 2017). There is also evidence that increased familiarity increases people's valuation of natural environment types. For example, although swamps, marshes, and deserts generally are the least preferred biome types in studies, even amongst populations that live near them (Balling \& Falk, 1982; Han, 2007; Hartmann \& Apaolaza-Ibáñez, 2010; Herzog, 1985; Jones et al., 1976; Lyons, 1983; Yabiku et al., 2008), there is evidence that the relative preference and valuation of these biome types increase with increased familiarity 
(Hammitt, 1980; Lyons, 1983; Yabiku et al., 2008). Similarly in ecological and goal oriented behavior research, there is evidence that behavior is influenced by frequent positive experiences with nature (singular experience effects tend to decline over time) (eg., Steg \& Vlek, 2009; Stern et al., 2008). This idea is also prominent in work on nature relatedness, which suggests that positive experiences in nature facilitate both the close subjective connection with nature, but also positive emotions and broader well-being (Nisbet et al., 2011). Although investigations with nature relatedness have made few distinctions among different environment types, the notion that spending time in nature promotes familiarity and liking natural environments is clear.

While the familiarity explanation receives support from existing research, an extreme version is contradicted by findings of natural environment preferences that transcend familiarity (e.g., swamps and deserts are never a favorite, Arctic mountains are highly preferred by Texans in Han (2007), Brazilian residents of three communities preferred non-local rainforests over local biome types in Moura (2018), see Section 1.2 for larger discussion). Therefore, despite these general trends, the overall results of existing natural environment type preference studies currently only allow for tentative conclusions due to some finding ambiguities and methodological limitations (see Section 1.2), particularly various studies providing contradictory evidence to both evolutionary and familiarity preference drivers. The confirmation of a clearly supported preference driver theory remains elusive. Methods to increase our understanding of natural environment preference drivers are discussed more in detail in Section 1.2.

\subsection{Assessing natural environment type preference methodologies}

In order to determine people's relative preference for the various natural environment types that are easily accessible to global human communities, and the driver(s) of their preferences, it is 
important to comprehensively evaluate a diverse array of local and foreign natural environment types, including those that have thus far been understudied and those that have been found to be preferred across diverse studies and contexts. Yet existing studies generally do not evaluate a broad enough range of natural environment types to further this research. For instance, a number of existing studies use a constrained set of natural environment types, which typically include a few natural environment types that are generally preferred (deciduous forests and to a lesser extent N. American cultivated parks), and several natural environment types that are generally not preferred (marshes and desert) (eg., Echeverri et al., 2017; Han, 2007). There is not enough diversity of preferred natural environment types to discern natural environment type preference drivers. For instance, existing studies that evaluate broader pools of natural environment types have found different relative preferences for these narrower biome type pools, in comparison to other, less commonly evaluated natural environment types (eg., Hartmann \& Apaolaza-Ibáñez, 2010), as discussed in the following subsection.

The importance of evaluating more diverse and relatively unevaluated natural environment types is demonstrated by (a) evidence that certain natural environment types may be generally preferred, regardless of familiarity, (b) several less studied natural environment types typically are highly preferred, oftentimes more than deciduous forests and parks, and (c) individual studies finding conflicting relative preferences of various natural environment types.

Mountains and several subtypes of waterscapes, particularly vegetated coastlines and lakes, and mountain integrated water bodies, are typically more preferred and most preferred, oftentimes irrespective of familiarity (eg., Han, 2007; Hartmann \& Apaolaza-Ibáñez, 2010; Herzog, 1985; Jones et al., 1976; White et al., 2010). This demonstrates that people prefer more diverse natural environment types than the results of narrow studies suggest. However, while 
individual studies provide support for certain natural environment types, there tends to be conflicting findings amongst different studies. Moreover, the limited natural environment type diversity in most studies, and their use of different natural environment types and assessment methodologies, makes it difficult to compare the results of various studies, and to ascertain people's natural environment type preferences, and their drivers. This demonstrates the need for more comprehensive and broad natural environment type studies. For instance, while mountain natural environment types have been found to be the most preferred natural environment type in several studies, even when participants are unfamiliar with mountains (eg., Han, 2007; Herzog, 1985), other studies have found mountains to be similarly preferred to other natural environment types (e.g., White et al., 2013), while in others they have been one of the least preferred (e.g., Echeverri et al., 2017). For example, in Hartmann \& Apaolaza-Ibanez (2010), a mountain creek was most preferred, yet forests with lakes and Mediterranean coastline were more preferred than a mountain lake, despite participants being more familiar with mountain landscapes than the Mediterranean coastline. Local forests were less preferred than all these types, and was the least preferred of the local natural environment types. While coastline visits were perceived as the most restorative in a study that evaluated the perceived restoration of visiting a broad range of natural and urban environment types by 4255 British residents, mountains and forests had comparable, but lower, restoration levels (White et al., 2013). In contrast, New Zealanders found forest features to be more important to their preferences than alpine features in Mosley (1989). Han (2007) found a Texas study sample preferred unfamiliar coniferous forests and arctic environments, particularly snow-covered mountains, substantially more than deciduous and tropical forests, as well as the more familiar deserts and grasslands, which were the least preferred. Interestingly, images with hills, mountains, and water bodies were substantially more 
preferred than flat and vegetation dominated images within every natural environment type. An image of dense enclosed coniferous forest was the least preferred image, while a lake bordered by coniferous forest and distant mountains was the most preferred, suggesting combinations of multiple natural environment types, or ecotones, may be highly preferred and should be further studied, as discussed in Section 4.

These results align with findings from other studies that have found differences in people's preferences of different sub-biome types and spatial qualities within similar natural environment types, which merits further investigation. For instance, different waterscape types have been found to be variably preferred more or less than other waterscape and terrestrial natural environment types (eg., Gundersen, Skår, O’Brien, Wold, \& Follo, 2016; Hartmann \& Apaolaza-Ibáñez, 2010). Herzog (1985) found mountain waterscapes, including waterfalls, streams, and lakes, to be most preferred, and least familiar, followed by large bodies of water,. Similarly, Jones et al. (1976) evaluated diverse waterscape types and found waterfalls and rapids to be the most enjoyable, followed by oceans, then swift rivers and streams, while marshes were the least preferred, followed by slow rivers and canals.. There is also evidence that waterscape preference is partially dependent on the type and proportion of topography, landscape, and/or vegetation in the scene (Hartmann \& Apaolaza-Ibáñez, 2010; Lee, 1979; Williams \& John, 2002).

These findings indicate that spatial qualities, proportions, and details within specific natural environments, can also influence preference between natural environment types, and merit further study. Nevertheless, there is relatively scant research on hybrid water-vegetation natural environment types and ecotones, despite generally high valuations for them (eg., Han, 2007; Jones et al., 1976; Peron et al., 2002; White et al., 2010). 
A number of natural environment types that are relatively common to diverse human communities have been relatively absent from existing studies. While tropical beaches and forests have received some attention, relative evaluations compared to more diverse waterscapes and landscapes are necessary to determine their relative valuation, and the potential mediating effects of participant familiarity (Echeverri et al., 2017; Hartmann \& Apaolaza-Ibáñez, 2010; White et al., 2010; Wyles et al., 2017).

In regards to evolution based preference driver studies, besides the general lack of breadth in natural environment types among the study samples, some studies that purport to demonstrate preferences for African savannah and forest natural environment types in actuality found support for environments similar to where they live, such as N. American urban parks and forests (eg., Balling \& Falk, 1982; Han, 2007). This complicates the discernment of preference drivers, as study participants tend to grow up playing in these park spaces, thereby supporting familiarity as well as a general preference for these natural environment types (Hartmann \& Apaolaza-Ibáñez, 2010; Lyons, 1983).

In order to evaluate the influence of familiarity on natural environment type preferences, participant familiarity of the specific environment types needs to be assessed. Unfortunately, the familiarity evaluation metrics used among existing studies are substantially inconsistent, and may vary in effectiveness. Some studies do not explicitly measure or evaluate the impact of familiarity on natural environment type preferences (e.g., Han, 2007; Morrow-Jones et al., 2006), whereas other studies evaluate participant familiarity via self-reporting (e.g., Echeverri et al., 2017; Hammitt, 1980), and a few have conducted more objective familiarity analysis. These include evaluating the impact of their hometown location and population size on their preference ratings (Balling \& Falk, 1982; Lyons, 1983), assuming which natural environment types are 
familiar via their presence in the local region (eg., Hartmann \& Apaolaza-Ibáñez, 2010; Moura et al., 2018), and self-reports of how many years participants have lived in the local region (eg. Yabiku, Casagrande, \& Farley-Metzger, 2008). In order to effectively evaluate the impact of familiarity on natural environment preferences, studies could account for factors that have been found to influence participant familiarity. These factors include hometown location, community type (urban, suburban, rural), and local natural environment types, current city location and community type, number of years living in hometown and current city, age, and self-reported familiarity with evaluated natural environment types.

Measuring and statistically accounting for all these factors is difficult, and an alternative approach is to compare the preferences of people selected from distinct geographical locations. This approach is unfortunately rare, and existing studies have some important limitations. For example, studies that have included participants from diverse geographic contexts tend to evaluate natural environment types from only one of the geographic contexts (e.g., Herzog et al., 2000; Kaplan \& Herbert, 1987), do not evaluate a broad range of familiar and unfamiliar natural environment types (e.g., Echeverri et al., 2017), or had highly variable or small sample sizes between test groups (e.g., 30 vs 518 samples in Balling \& Falk, 1982). While Moura et. al. (2018) comparatively evaluated the six relatively common biome types amongst populations with different local natural environments, there was a dearth of highly preferred natural environment types included in the study that are similarly accessible as the most preferred type, tropical rainforests, to the participants, including tropical beaches. The sample images did not control for several influential variables: leaf cover amongst image samples varied from winter, fall, and spring season, both mountain and flat versions of various biome types were included, etc. Notably, although tropical rainforests were most preferred, their sample images were of 
mountainous tropical forests, not eye level immersive images such as the coniferous forest image samples. It is thus not possible to determine the extent that the mountain and flat immersive images of the various samples and biome types influenced the responses. Moreover, while multiple communities were evaluated with different local natural environments, they were all from the same country (Brazil), wherein tropical rainforests are deeply ingrained in their culture and history. The potential impact of including participants from a substantially contrasting geographic context may have helped clarify the results.

\subsection{Current study}

In sum, although theories and research have begun to elucidate people's preferences for various natural environment types, results are often mixed and limited in their comparisons. The many gaps cannot be filled by a single study, but we tried to expand on the typical breadth of natural environments in our investigation. The primary goal of the current study was to better understand which natural environments are more preferred than others, and the degree to which such differences are explained by familiarity versus more specific natural environment preference theories and drivers (e.g., forest, savannah). To this end, we built on past work by having research participants rate images representing a wide variety of natural environments (10, via 4 specific examples of each). These ratings included positive qualities of the environments (e.g., restorativeness, safety, beauty), as well as subjective familiarity. Familiarity was also considered more objectively and implicitly by contrasting ratings from two distinct geographical regions. That is, we recruited samples from Ottawa, Ontario in Canada and Fort Lauderdale, Florida in USA, and asked them to rate natural environments selected to be particularly familiar (or not) to that location (e.g., beaches vs. temperate forests). These design features frame our primary research questions: does familiarity predict positive perceptions of environments, and 
does the link with familiarity depend on whether we consider subjective self-ratings versus objective location data? In addition, our methods are well-suited to determining which natural environments are more and less preferred across a wider range than is typically studied. For example, we (hypothetically) could find that all natural environments with water are preferred to those without. Our approach is then also well-suited to examine the relative importance of familiarity versus natural environment type in preferences. Based on past work, we predicted that familiarity would be important to preferences, but also that some natural environment types (beaches, mountains, lakes, parks) would be preferred to others (swamps, marshes), regardless of familiarity. With many mixed results already reported, we did not anticipate clear support for savannah or forest preference drivers.

In addition, other features of our method address supplemental research questions. First, we collected data from Ottawa raters in both winter and fall seasons to understand if current weather conditions were important to natural environment type preferences (cf. Han, 2007), e.g., does the beach look better during a Canadian winter? We also attempted to assess a variety of potentially distinct natural environment qualities such as restorativeness, safety, and whether the biome was a place people would want to live nearby, as some past research suggests tradeoffs among these different framings/features. Finally, we explored the role of trait nature relatedness in ratings of both familiarity and natural environment type evaluations; we suspected that highly nature related people would be more familiar with and would more positively evaluate all (natural) environments, compared to more disconnected people.

\section{Method}

The same study was conducted across three separate samples. For conciseness, the samples are described individually and then the overall materials and procedure are described. 
We report all data exclusions, manipulations (none), and measures included in the study (as recommended by Simmons, Nelson, \& Simmonsohn, 2012). Target sample sizes were determined by a loose rule of thumb to get 300 cases, but fewer participants were available in Fort Lauderdale; we did not look at data before stopping collection. Data and materials are available at: https://osf.io/4vbrj/?view_only=0e363468b9924bddb17c8031321ea295

\section{Participants Sample 1}

A total of 302 participants completed the study "Viewing and Rating Various Photographs" for course credit (about 35 minutes of their time) during the winter semester of 2016 in Ottawa, Ontario. The participants were recruited through the Psychology Department's online sign-up system (SONA). Responses that were almost entirely blank or if participants spent less than 15 minutes on the questionnaire were deleted $(n=15)$, therefore analyses were conducted with 287. Participants ranged in age from 17 to $48(M=20.70, S D=5.05)$ and $82 \%$ were in their first or second academic year. The majority of the sample was female $(71 \%)$. The mean time participants have lived in Ottawa was 9.38 years $(S D=9.85$, range $=0-44)$. Close to the majority of participants grew up in a suburban city (48\%), followed by a small town (22\%), downtown city (14\%), or rural farm (4\%). Most participants grew up in Ontario (54\%); relatively fewer participants grew up elsewhere in Canada (7\%) or internationally $(17 \%)$.

\section{Participants Sample 2}

A total of 160 participants completed the study "Viewing and Rating Various Photographs" for course credit in the summer semester of 2016 (about 35 minutes of their time) in Fort Lauderdale, Florida. The participants were recruited through a psychology course (participants who were not registered in the class but still wanted to complete the study were 
allowed). Responses that were almost entirely blank or if participants spent less than 15 minutes on the questionnaire were deleted $(n=12)$, therefore analyses were conducted with $n=148$. Participants ranged in age from 18 to $46(M=22.75, S D=4.02)$ and most participants $(58 \%)$ were in their third academic year (only 3\% were in their first year, $6 \%$ in their second year, and $24 \%$ in their fourth). The majority of the sample was female (57\%). The mean time participants have lived in Florida was 15.37 years $(S D=8.17$, range $=0-33)$. Many participants grew up in a suburban city (59\%), and a few grew up in a downtown city (7\%), small town (19\%), or rural farm $(1 \%)$. Most participants grew up in Florida (62\%), with a minority growing up in other parts of the United States (22\%), and other countries (7\%).

\section{Participants Sample 3}

A total of 328 participants completed the study "Viewing and Rating Various Photographs" for course credit in the fall semester 2016 in Ottawa, Ontario. The participants were recruited through the Psychology Department's online sign-up system (SONA). Responses that were almost entirely blank or if participants spent less than 15 minutes on the questionnaire were deleted $(n=43)$, therefore analyses were conducted with $n=285$. Participants ranged in age from 17 to $49(M=20.07, S D=5.04)$ and $61 \%$ were in their first academic year. The majority of the sample was female (75\%). The mean time participants have lived in Ottawa was 8.69 years $(S D=8.73$, range $=0-33)$. Many participants grew up in a suburban city $(48 \%)$, and a few grew up in a downtown city (16\%), small town (26\%), or rural farm (7\%). Most participants grew up in Ontario (64\%), elsewhere in Canada (8\%) or international (15\%).

\section{Materials}


Photos. Participants viewed 40 photos that represented 10 biomes, or 4 images per biome type, eg. Figures 1 and 2. In terms of biome type selection for this study, natural environment preference studies tend to concentrate on evaluating several biome types, with five to seven terrestrial biome types being the most common (savannah, temperate deciduous forest, swamp, tropical forest, desert, and sometimes coniferous forest generally are the most common). However, there is not yet a settled definition for the range of existing biome types (eg., Odum, 1993; Olson et al., 2001), and as discussed in Section 1, natural environment type preferences are more nuanced than existing general biome type ranges can capture. However, comprehensively evaluating all preference nuances within one study represents a number of challenges and risks to developing informative results, as discussed in Section 4. While both breadth of biome types and depth of natural environment types (evaluating diverse sub-biome types) are important to evaluate to clarify natural environment type preference drivers, this study focused on evaluating potential familiarity preference drivers and a broad range of biome types, including several less commonly evaluated, yet often highly preferred biome types (eg., beach and mountain). In addition to contributing to the evaluation of preference drivers, the broad biome type approach also was chosen because the results can help guide the focus of future studies by identifying biome types that may offer further preference driver insights if they are evaluated at the subbiome type level, as discussed in more detail in Section 4.

In order to evaluate the desired preference driver factors, biomes that were present in the local regions of the two strategically selected sample populations were prioritized in our selection process. Some biomes, such as lakes, rivers, temperate forests, Ottawa type marshes, and open meadows are more representative of the Ottawa, Ontario region biome types. Beaches, tropical forests, and Florida swamps are more representative of the Fort Lauderdale, South 
Florida biome types. Images of typical North American urban parks were included as a general biome type found in both regions. While urban parks have not been classified as a biome type in ecological biome classification systems, they are a globally prevalent vegetated environment type amongst global urban areas that has been evaluated extensively in existing natural environment preference studies. Mountains were included as a biome type not typical to either location (though closer to Ottawa), but that have been generally preferred regardless of familiarity in previous studies (see Section 1.2).

Sample images were selected based on their representativeness of their relevant natural environment type. Eye level images were chosen to ensure comparability with previous studies, as existing studies generally include immersive eye level biome type sample images (see Figures 1 and 2). Vibrant colors, particularly bright flowers, were avoided as they've been found to influence preferences in some studies (eg., Kardan et al., 2015; Lindemann-Matthies \& Bose, 2007). Specifically, our study includes grass dominated meadows, as the colors of flower dominated meadows would be a striking contrast to the other sample biome types, thereby introducing a substantial variable to our study, which is primarily focused on evaluating a broad range of biome types. 


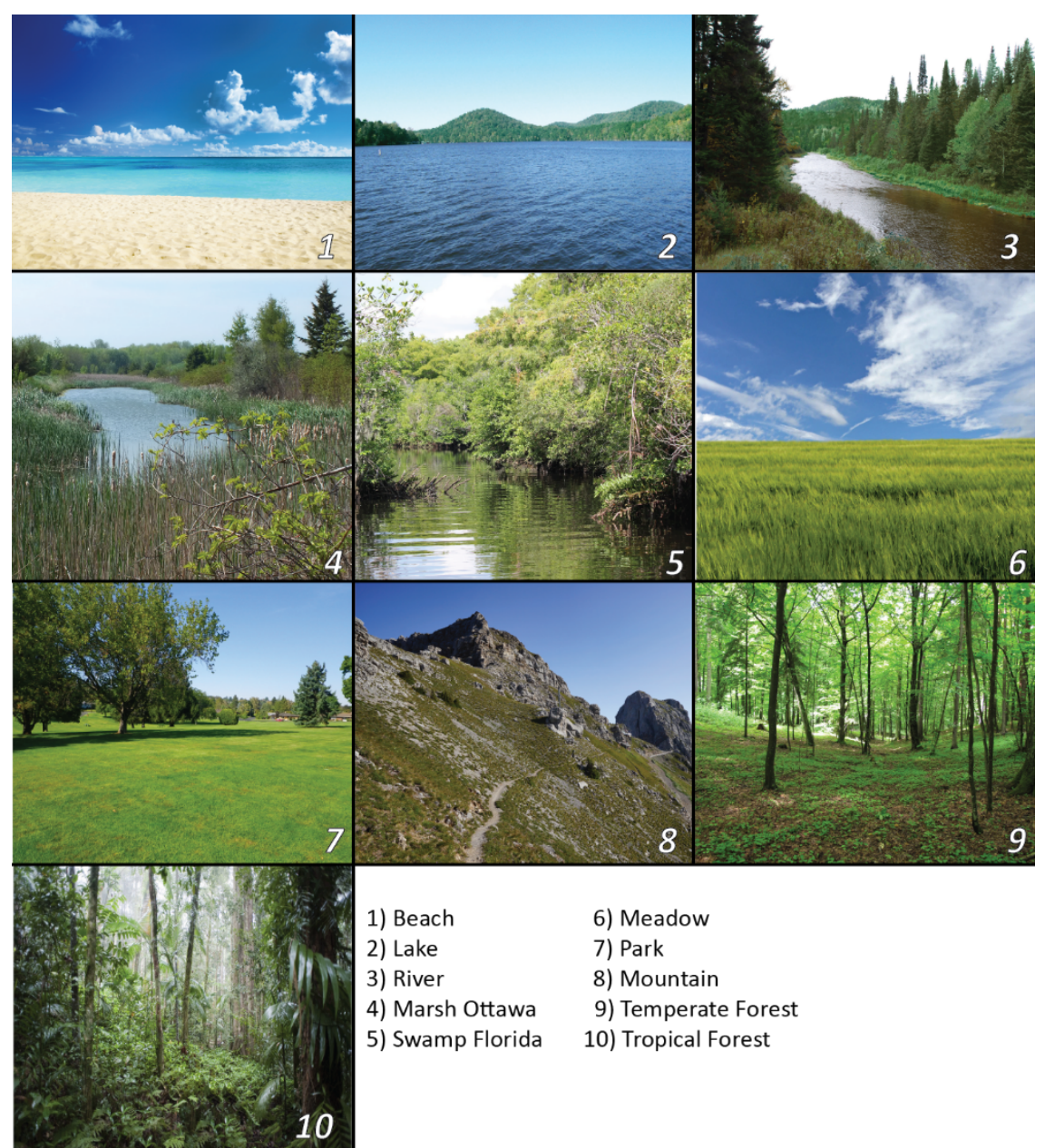

Figure 1: Sample Biome Types Images

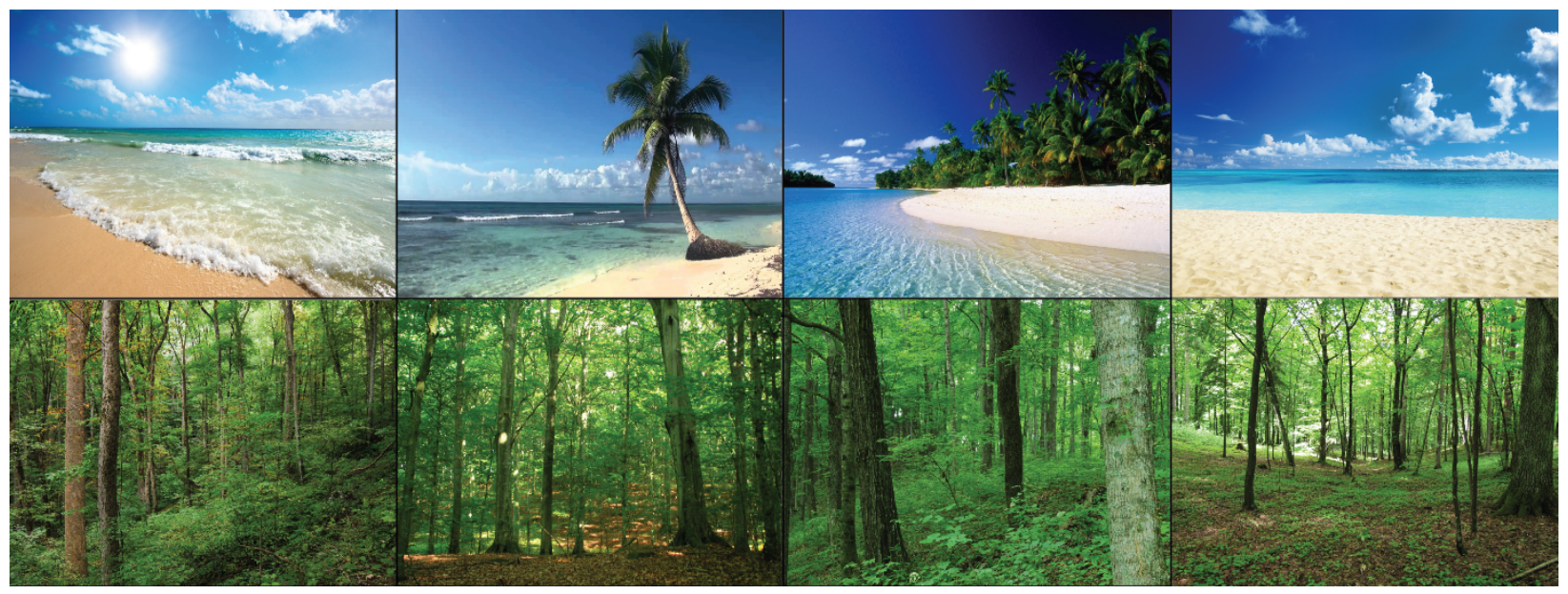

Figure 2: Beach and Forest Biome Type Images (Ordered left to right: 1-4) 
Photo Ratings. We sought to measure many previously studied qualities of biomes, yet also to avoid fatiguing participants who completed the questions for each of 40 photos. Ultimately, 13 items appeared under each photograph; items asked participants to rate how much they thought each picture represented a quality, or for agreement with a statement on a scale from 1 to 7 (see supplement). Anchors depended on the specific items (e.g., 'not at all beautiful' to 'very beautiful' or 'strongly disagree' to 'strongly agree'). We chose a broad range of items, mostly drawing on past research, but largely assembled individually and ad hoc (vs. one standard questionnaire) to represent constructs of interest. Participants first rated their overall liking 'for whatever reason', the standard item used for evaluating natural environment type preferences in existing studies (eg., Hammitt, 1980; Han, 2007). Several studies have alternatively used questions on the desirability of the natural environment type as a place to live adjacent to or visit as a preference metric, so participants were asked to rate how much they would want to live adjacent to the biome/location, so the results of both metrics could be compared (Balling \& Falk, 1982; Lyons, 1983). They then rated three relatively non-aesthetic qualities: how familiar, how safe (Tabrizian et al. 2018), and how public (Mangone et al, 2017) the picture was. Next, three items assessed aesthetics and positive feelings: how beautiful, pleasant, and relaxing the picture was (Dopko et al., 2014; T. Hartig et al., 1997; Kuller, 1972). The final five items were drawn from the Perceived Restorativeness Scale's fascination and being away subscales (Pasini et al., 2014) and rated on a scale of agreement, for example, "Places like this are fascinating," and "Places like this are a refuge from nuisances." Items were presented in the same order for each photo; see Supplement for full text of all items. 
Although our intention was to separately measure various features of each biome (e.g., preference, safety, restoration), preliminary analyses revealed substantial overlap (i.e., very high correlations among most ratings). After aggregating ratings across the four photos for each biome, we scanned correlation tables and conducted various exploratory factor analyses. Although there is not a single quantitative result that fully describes the pattern (given separate analyses across 10 biomes), it became apparent that most ratings cohered into a single dimension of pleasantness or positivity (this can be seen in Table 1). As such, 11 ratings were averaged into a single positivity score for each biome, omitting only familiarity and how public the images were rated. Familiarity was omitted because: a) it tended to correlate less strongly with other ratings and form another factor, b) it is not clearly positive or negative, and c) was a separate, focal construct of interest in this study. The 'public' ratings were also excluded from the aggregate due to comparatively low correlations with other items, which is unsurprising given its relative neutrality. Public ratings for each biome are provided in the online supplement, as well as their correlations with our focal positivity and familiarity variables. People who rated biomes as public also tended to rate them as more positive and familiar, but with correlations that were generally weaker than the links among other positive items and the link between positivity and familiarity.

Analyses focused on the single item familiarity ratings, and the composite positivity ratings (where alphas range from .93 to .98 across 10 biomes). The focus on positivity ratings acknowledges that our data cannot distinguish among the more specific features well. So, for example, anything that is true of the general positivity composite is likely true of perceived restorativeness; yet, it is very likely true of safety and beauty too-we cannot make the finer distinctions in these data. As another important example, we infer that these broad positivity 
ratings are roughly equivalent to preferences. This inference is supported by the very strong correlations between the single-item typically used to assess preference and our positivity composite, ranging from $r=.85$ to $r=.93$ across biomes. Descriptive statistics for the positivity of each photo are provided in the Supplement. Variability within biomes was generally low. For example, the beach arguably had the most distinct variation between samples ( 2 with vegetation, 2 without, see Figure 2), which has been found to influence preferences in existing studies (eg., White et al., 2010). Yet the means were within 0.2 standard deviations among the four photos in the beach, the same as the much less distinctive temperate forest set (see Figure 2). A couple idiosyncratic photos in other biomes (parks, marshes) had means nearly a full standard deviation from others in their sets. Even this variation is not extreme, and supports our choice to sample multiple photos.

Short Nature Relatedness Scale (NR; Nisbet \& Zelenski, 2013). Participant's perceived level of connection to nature at the trait level was evaluated using the established 6item 'short version nature relatedness scale.' An example item is, "I take notice of wildlife wherever I am.” This scale demonstrated acceptable internal consistency, alpha $=.87$.

Demographics. Participants completed a series of questions that asked about where they spent the majority of their childhood (e.g., urban, small town), their hometown (specifically), how long they have lived in Ottawa/South Florida, age, gender, current year of study.

\section{Procedure}

Participants completed the study online via the Qualtrics platform. After giving informed consent, participants began the study by viewing and rating 40 photographs of different nature environments (one at a time) and rated each image. The photos were presented in a randomized 
order. Participants then completed the personality measure of nature relatedness and the demographic questions. The median time to complete the study was 35 minutes, after selection criteria that excluded responses $<15$ minutes.

\section{Results}

\section{Preliminary Analyses}

All analyses were conducted with IBM SPSS version 26. As noted in the methods section, high correlations among the various biome ratings led us to create a composite score for positivity that included all ratings except familiarity and publicness. To provide some further insight into our scoring choices, we present the inter-correlations for two biomes as examples in Table 1 (correlations for all biomes are in the online supplement). The beach biome was least representative of overall patterns, with the lowest correlations among items. We include it for this reason (i.e., as the 'worst case') and also because it is the most prototypical biome for the Fort Lauderdale sample. We compliment this with the correlations for the temperate forest biome, which is most prototypical of Ottawa, and also fairly representative of the large correlations observed with most other biomes. 
Table 1

Beach and Temperate Forest Photo Ratings

\begin{tabular}{|c|c|c|c|c|c|c|c|c|c|c|c|c|}
\hline & 1. & 2. & 3. & 4. & 5. & 6. & 7. & 8. & 9. & 10. & 11. & 12. \\
\hline 1. Like & - & $.80 * * *$ & $.68 * * *$ & $.75^{* * *}$ & $.16^{* * *}$ & $.88 * * *$ & $.88 * * *$ & $.87 * * *$ & $.83 * * *$ & $.79 * * *$ & $.76^{* * *}$ & $.75 * * *$ \\
\hline 2. Live & $.73 * * *$ & - & $.68 * * *$ & $.80 * * *$ & $.18^{* * *}$ & $.71 * * *$ & $.76^{* * *}$ & $.77 * * *$ & $.69 * * *$ & $.68 * * *$ & $.69 * * *$ & $.69 * * *$ \\
\hline 3. Familiar & $.37 * * *$ & $.48 * * *$ & - & $.73 * * *$ & $.14 * * *$ & $.62 * * *$ & $.68 * * *$ & $.67 * * *$ & $.55 * * *$ & $.54 * * *$ & $.56 * * *$ & $.56^{* * *}$ \\
\hline 4. Safe & $.54 * * *$ & $.63 * * *$ & $.51 * * *$ & - & $.21 * * *$ & $.68^{* * *}$ & $.73 * * *$ & $.76^{* * *}$ & $.64 * * *$ & $.64 * * *$ & $.67 * * *$ & $.68 * * *$ \\
\hline 5. Public & $.09^{*}$ & $.14 * * *$ & $.38 * * *$ & $.27 * * *$ & - & $.13 * *$ & $.17 * * *$ & $.18^{* * *}$ & $.20 * * *$ & $.20 * * *$ & $.22 * * *$ & $.16^{* * *}$ \\
\hline 6. Beautiful & $.80 * * *$ & $.62 * * *$ & $.33 * * *$ & $.49 * * *$ & $.09 *$ & - & $.92 * * *$ & $.88^{* * *}$ & $.85 * * *$ & $.80 * * *$ & $.74 * * *$ & $.73 * * *$ \\
\hline 7. Pleasant & $.85^{* * *}$ & $.70 * * *$ & $.38 * * *$ & $.58 * * *$ & $.11 * *$ & $.88 * * *$ & - & $.93 * * *$ & $.85^{* * *}$ & $.81 * * *$ & $.76 * * *$ & $.78 * * *$ \\
\hline 8. Relaxing & $.84 * * *$ & $.71 * * *$ & $.37 * * *$ & $.58 * * *$ & $.10^{*}$ & $.82 * * *$ & $.93 * * *$ & - & $.82 * * *$ & $.79 * * *$ & $.76^{* * *}$ & $.79 * * *$ \\
\hline 9. Fascinating & $.72 * * *$ & $.62 * * *$ & $.39 * * *$ & $.53 * * *$ & $.16^{* * *}$ & $.68^{* * *}$ & $.73 * * *$ & $.69 * * *$ & - & $.93 * * *$ & $.85 * * *$ & $.73 * * *$ \\
\hline 10. Interesting & $.60 * * *$ & $.57 * * *$ & $.41^{* * *}$ & $.51 * * *$ & $.22 * * *$ & $.57 * * *$ & $.64 * * *$ & $.60 * * *$ & $.87 * * *$ & - & $.89 * * *$ & $.72 * * *$ \\
\hline 11. Bored & $.58 * * *$ & $.60^{* * *}$ & $.40 * * *$ & $.55 * * *$ & $.23 * * *$ & $.53 * * *$ & $.61 * * *$ & $.58 * * *$ & $.76^{* * *}$ & $.84 * * *$ & - & $.74 * * *$ \\
\hline 12. Nuisances & $.53 * * *$ & $.49 * * *$ & $.28 * * *$ & $.43 * * *$ & $.09 *$ & $.49 * * *$ & $.58 * * *$ & $.58 * * *$ & $.50 * * *$ & $.48^{* * *}$ & $.54 * * *$ & - \\
\hline 13. Attention & $.67 * * *$ & $.66 * * *$ & $.49 * * *$ & $.53 * * *$ & $.14 * * *$ & $.60 * * *$ & $.68 * * *$ & $.70 * * *$ & $.65 * * *$ & $.64 * * *$ & $.62 * * *$ & $.62 * * *$ \\
\hline
\end{tabular}

Note. ${ }^{*} p<.05, * * p<.01, * * * p<.001$. Beach is below the diagonal, $N=707-708$. Temperate Forest is above the diagonal, $N=708$. 
Although we collected two separate samples from Ottawa, they are combined in the main results. The second sample was sought to examine if results in the first were due to seasonality. For example, that beaches were rated so positively because data were collected during a long Canadian winter with less sunlight hours and colder temperatures (cf. Han [2007] which suggested season variations in biome preferences). To assess the plausibility of seasonal differences, we compared the overall liking and familiarity ratings for Ottawa samples collected during the fall term (sample 3) versus the winter term (sample 1). Of the 20 tests, none were statistically significant at the $p<.05$ level, despite high power. Two tests met the criterion of $p<$ .10. Although this frequency is expected by chance alone, one difference was the liking of the beach, $t(561)=1.73, p=.09, d=.15$, with the beach being more slightly preferred by the winter sample (5.93 vs. 6.07$)$; the meadow was also slightly more preferred by the winter sample, $t$ $(560)=1.70, p=.09, d=.14,(4.30$ vs. 4.47). Although these small differences might intrigue, we interpret these analyses as indicating overwhelming similarity across Ottawa fall and winter samples, and we combined them for simplicity in other analyses. Said another way, the differences across the Ottawa samples are considerably smaller than differences with the Fort Lauderdale sample (see Tables $2 \& 3$ ).

Part of our strategy involved comparing participants selected from different locations (Ottawa vs. Fort Lauderdale). In examining our data, we learned that there was some diversity in where people grew up, regardless of their current location (e.g., international students as the most extreme case). To address this issue, we repeated all focal analyses with a stringent criterion that included only participants who reported growing up within $100 \mathrm{~km}$ of Ottawa $(n=223)$ or Fort Lauderdale $(n=71)$. These results are reported in the online supplement, but are generally very similar to results with the complete samples reported here. 


\section{Familiarity and Biome Preferences}

We tested the link between familiarity and biome positivity (preferences) with two approaches. The first examines correlations between individuals' ratings of personal familiarity and their positive assessments of biomes; it addresses the question, 'do the people most familiar with a biome, for whatever reason, like it more than others?,' focusing on rank-orders within each biome, rather than mean levels across them. The second approach infers familiarity based on physical location (Ontario vs. Florida), to see if the objectively prominent biomes are also rated more positively; this approach depends more on how the mean levels of each biome compare to one another.

In the first approach, we computed correlations to test the hypothesis that people would like biomes that are perceived as more familiar, see Table 2. For every biome type, overall perceived biome positivity was significantly and fairly strongly correlated with familiarity. That is, as familiarity increased so did the perceived positivity of the biome or vice versa. This is consistent with prior research, and the idea that familiarity facilitates liking (though causality could run the other way). 
Table 2

Correlation between Overall Perceived Biome Positivity and Familiarity

\begin{tabular}{|c|c|c|c|}
\hline & Overall correlation & Ottawa correlation & $\begin{array}{l}\text { Fort Lauderdale } \\
\text { correlation }\end{array}$ \\
\hline Beach & $.50 * * *$ & $.47 * * *$ & $.50 * * *$ \\
\hline Swamp Florida & $.60 * * *$ & $.65 * * *$ & $.58 * * *$ \\
\hline Tropical Forest & $.51 * * *$ & $.50 * * *$ & $.60 * * *$ \\
\hline Park & $.46 * * *$ & $.44 * * *$ & $.62 * * *$ \\
\hline Mountain & $.47 * * *$ & $.45 * * *$ & $.55 * * *$ \\
\hline Open Meadow & $.58 * * *$ & $.60 * * *$ & $.61 * * *$ \\
\hline River & $.65 * * *$ & $.68 * * *$ & $.54 * * *$ \\
\hline Lake & $.66^{* * *}$ & $.68 * * *$ & $.62 * * *$ \\
\hline Marsh Ottawa & $.68 * * *$ & $.68 * * *$ & $.68 * * *$ \\
\hline Temperate Forest & $.71 * * *$ & $.70 * * *$ & $.73 * * *$ \\
\hline
\end{tabular}

Note. $* * * p<.001$. For overall correlations, $N=706-709$. For Ottawa correlations, $N=559$ 563. For Fort Lauderdale correlations, $N=144-146$.

In the second approach, we selected biomes such that some were more available to participants in Ottawa and others to participants in Fort Lauderdale. To test our assumptions about which biomes were more familiar in each location (cf. a manipulation check), we compared Ottawa and Fort Lauderdale participants' subjective assessments of the biome photos 
with $t$-tests, displayed in Table 3. As expected, participants in Ottawa rated biomes that are more common in Ottawa as higher on familiarity (e.g., river, open meadow, lake, Ottawa marsh, temperate forest), compared to participants in Florida. Participants in Fort Lauderdale rated biomes that are more common in Fort Lauderdale as higher on familiarity (e.g., beach, Florida swamp, tropical forest). The mountain biome was not significantly different in familiarity between Ottawa or Fort Lauderdale participants, consistent with the fact that mountains are not locally present in either location. In other words, participants largely corroborated the typicality (familiarity) of selected biomes when comparing across the Fort Lauderdale and Ottawa groups. It is worth noting, however, that the Ottawa samples rated the beach as quite familiar (4.88), compared to some other local biomes that are actually more abundant there (e.g., Ottawa marsh = 3.66 , river $=4.20)$, so the raw rank orders are more ambiguous.

More importantly, our second methodological approach allows us to test the link between familiarity and positivity by comparing two physical locations. That is, we compared positivity ratings for different biomes among Fort Lauderdale and Ottawa samples, an approach that is perhaps more objective with respect to familiarity. Results of these comparisons reveal more mixed support for the idea that familiarity produces liking. In support, it seems that Ottawa residents rated some familiar biomes significantly more positively than Fort Lauderdale residents, e.g., temperate forests and Ottawa marshes. Similarly, Fort Lauderdale residents rated the beach as significantly more positive, compared to Ottawans. On the other hand, some comparisons were more problematic for the familiarity hypothesis. First, Ottawans rated some Florida-typical biomes as more positive than did the Fort Lauderdaleans (e.g., Florida swamp, tropical forest), and Fort Lauderdaleans rated the open meadow more positively than did Ottawans. Also, looking at the mean levels of all ratings reveals that Ottawans rated the (Florida) 
beach as the single most positive place, more so than the temperate forest, even though it was objectively less familiar. 
Table 3

Mean familiarity and positivity differences across locations

\begin{tabular}{|c|c|c|c|c|c|c|}
\hline & Familiarity & & & Positivity & & \\
\hline & Ottawa & $\begin{array}{l}\text { Fort } \\
\text { Lauderdale }\end{array}$ & Difference & Ottawa & $\begin{array}{l}\text { Fort } \\
\text { Lauderdale }\end{array}$ & Difference \\
\hline Biome & $M(S D)$ & $M(S D)$ & Cohen's $d$ & $M(S D)$ & $M(S D)$ & Cohen's $d$ \\
\hline Beach & $4.88(1.66)$ & $6.36(1.04)$ & $1.07 * * *$ & $6.00(.94)$ & $6.42(.70)$ & $.51 * * *$ \\
\hline Swamp Florida & $3.23(1.30)$ & $3.86(1.59)$ & $.43 * * *$ & $3.96(1.21)$ & $3.62(1.34)$ & $.27 * *$ \\
\hline Tropical Forest & $2.87(1.40)$ & $3.36(1.59)$ & $.33 * * *$ & $4.24(1.23)$ & $3.96(1.43)$ & $.21 *$ \\
\hline Park & $5.48(1.20)$ & $5.25(1.27)$ & $.19 *$ & $4.62(1.01)$ & $5.04(1.02)$ & $.41 * * *$ \\
\hline Mountain & $3.32(1.49)$ & $3.28(1.71)$ & .02 & $4.85(1.21)$ & $4.76(1.34)$ & .07 \\
\hline Open Meadow & $4.40(1.44)$ & $4.08(1.56)$ & $.21 *$ & $4.38(1.18)$ & $4.79(1.21)$ & $.34 * * *$ \\
\hline River & $4.20(1.39)$ & $3.73(1.59)$ & $.31 * *$ & $4.70(1.19)$ & $4.60(1.29)$ & .08 \\
\hline Lake & $5.29(1.41)$ & $4.41(1.53)$ & $.60 * * *$ & $5.36(1.05)$ & $5.17(1.22)$ & $.17^{\dagger}$ \\
\hline Marsh Ottawa & $3.66(1.51)$ & $3.37(1.50)$ & $.19^{*}$ & $3.51(1.29)$ & $3.21(1.32)$ & $.23 *$ \\
\hline $\begin{array}{l}\text { Temperate } \\
\text { Forest }\end{array}$ & $4.93(1.53)$ & $3.79(1.60)$ & $.73 * * *$ & $4.69(1.30)$ & $4.28(1.39)$ & $.30 * * *$ \\
\hline
\end{tabular}

Note. ${ }^{* *} p<.001 * * p<.01,{ }^{*} p<.05$ for associated $t$-tests. $n=559-563$ for Ottawa location, $n$ =144-146 for Fort Lauderdale location. Biomes are ordered from those anticipated to be most familiar in Florida (top) to most familiar in Ontario (bottom). 


\section{Other approaches to Biome Preferences}

Although our methods focused on testing the familiarity hypothesis, we collected preference data across many biomes. Differences across these ratings speak to other views about which biomes are preferred, and help put the familiarity findings in perspective. Figure 3 presents the biome positivity data from Table 2, but ordered from top to bottom by the average positivity (across both samples). In essence, the figure ranks the most preferred biomes, regardless of familiarity. Comparisons between different biomes have very high statistical power (all participants rated all biomes so act as their own comparison across biomes); thus, even small differences are statistically significant at $p<.05$. For example, looking at overall preferences (across all participants), the difference between park (4.71) and river (4.68) is not statistically significant, but the difference between park (4.71) and temperate forest (4.61) is right at the threshold, $p=.055$. Statistically significant within-person biome-to-biome comparisons are, in some cases, substantially smaller than the (non)significant between-group differences, and therefore not very meaningful. With this in mind, a visual inspection and interpretation of the figure is more productive than significance testing.

In essence, Figure 3 shows substantial variation in positivity ratings across the biomes. There is also substantial agreement across the Ottawa and Fort Lauderdale samples in which biomes are most preferred. Everyone seems to agree that beaches and lakes are nice, and that swamps and marshes are not. This provides some mixed support for the notion that people prefer blue spaces. Although mountains are not locally present for our participants, they are viewed as similarly positive to parks and rivers, which are more common locally, especially in Ottawa. Some of our results do support the notion that familiarity contributes to a positive evaluation of biomes (i.e., correlations and location comparisons). However, Figure 3 clarifies that the 
familiarity effects play out across substantial differences in biome evaluations that have nothing to do with familiarity. This notion is underscored by comparing Figure 3 to Figure 4 . Figure 4 presents the familiarity ratings from Table 3, ordered by positivity as in Figure 3. Consistent with our design choices, the two locations produce more divergent familiarity ratings. Still, comparing Figures 3 and 4 gives some sense of how mean positivity and familiarity (mis)align across biomes. In sum, familiarity may impact people's preferences, but the actual biomes under consideration (e.g., mountains vs. swamps) matters too, and sometimes more than familiarity.

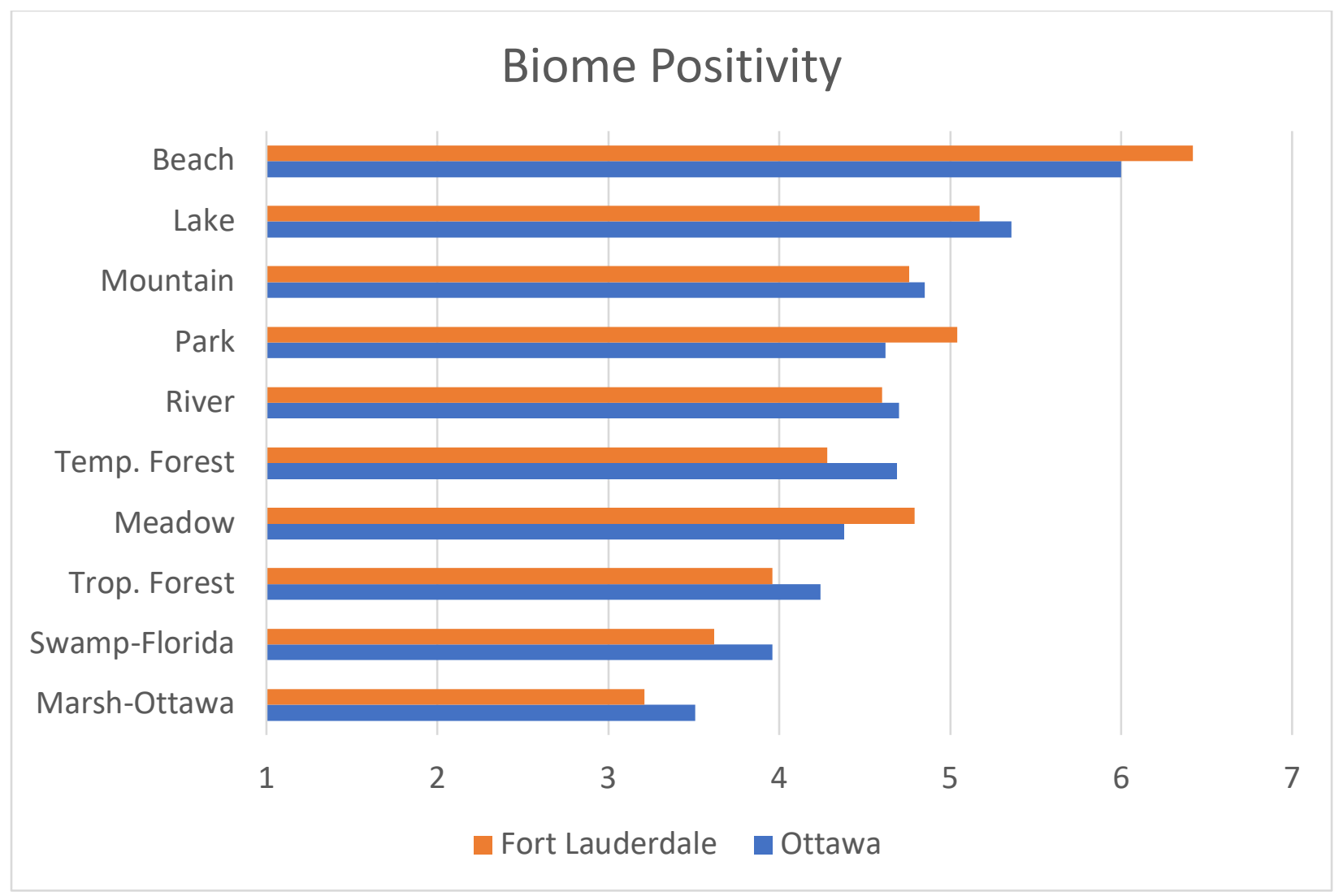

Figure 3. Biome type preferences, ordered from most to least positive, top to bottom. 


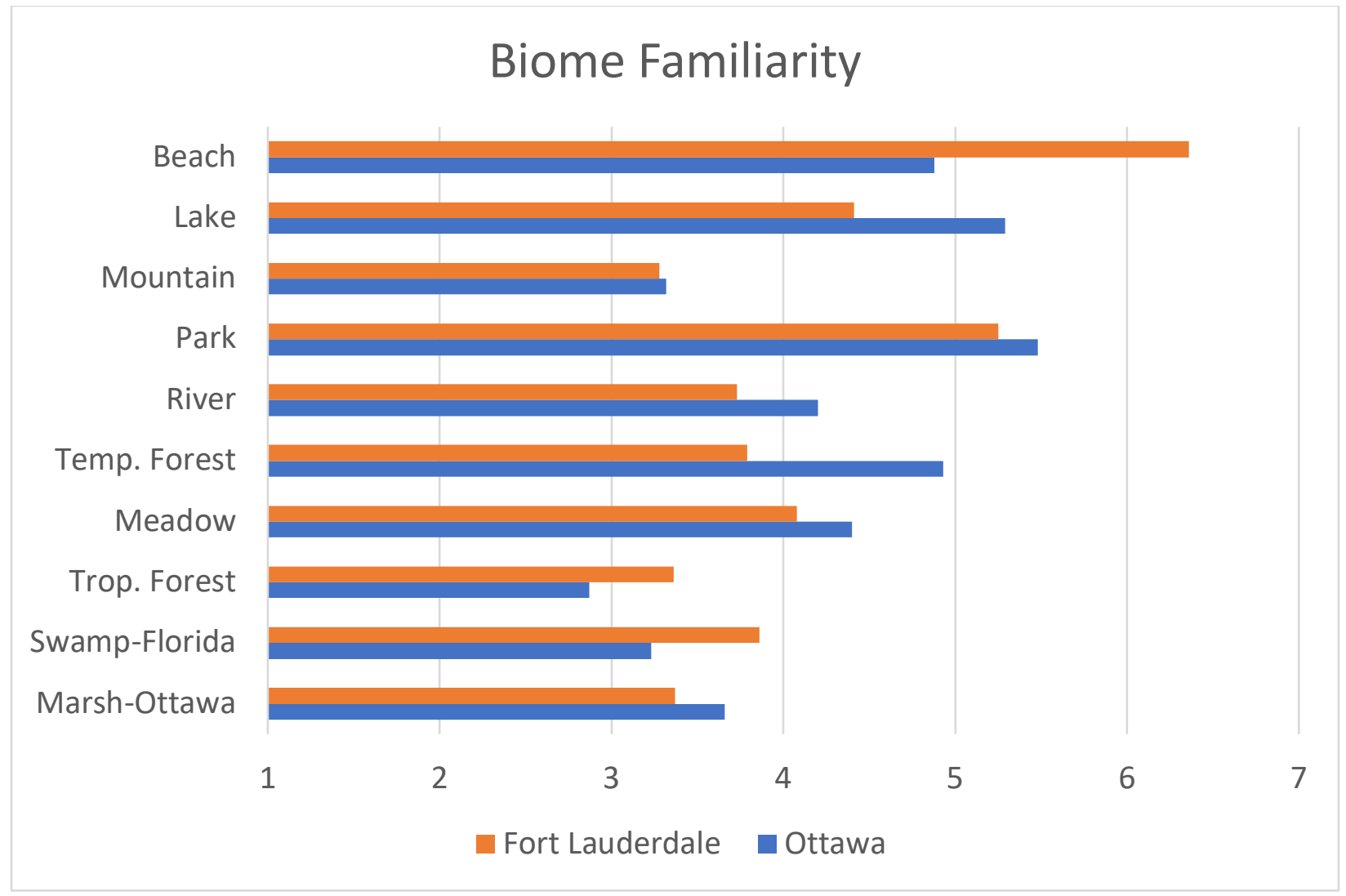

Figure 4. Biome type familiarity, ordered from most to least positive, top to bottom.

\section{Individual Differences in Nature Relatedness}

In order to examine a final exploratory hypothesis, nature relatedness was correlated with the overall positivity and familiarity of each biome (Table 4). Nature relatedness was positively correlated with both positivity and familiarity for all biomes except the beach. This finding suggests that participants who were more connected to nature generally found natural biomes to be more beautiful, pleasant, and relaxing, etc., compared to participants who feel less connected to nature. The positive correlations with familiarity are also broadly consistent with the idea that nature related people spend more time in nature. Given the many significant associations among nature relatedness, familiarity, and positivity, we also conducted regression analyses to simultaneously test the predictive power of nature relatedness and familiarity on positivity 
ratings. For all environments except the beach (where nature relatedness was not associated with positivity), both familiarity and nature relatedness independently predicted positivity (all $p<$ .006). Familiarity was also the stronger predictor, like the correlations, and sensible given that familiarity ratings were for the same specific photos as the positivity ratings, whereas nature relatedness is a generalized trait and not specific to any natural environment. 
Table 4

Correlations between Nature Relatedness, Biome Positivity, and Familiarity

\begin{tabular}{|c|c|c|}
\hline Biome & Positivity & Familiarity \\
\hline 1. Beach & -.04 & -.05 \\
\hline 2. Swamp Florida & $.42 * * *$ & $.32 * * *$ \\
\hline 3. Tropical Forest & $.39 * * *$ & $.19 * * *$ \\
\hline 4. Park & $.17 * * *$ & $.17 * * *$ \\
\hline 5. Mountain & $.38 * * *$ & $.25 * * *$ \\
\hline 6. Meadow Open & $.26 * * *$ & $.19 * * *$ \\
\hline 7. River & $.44 * * *$ & $.37 * * *$ \\
\hline 8. Lake & $.34 * * *$ & $.29 * * *$ \\
\hline 9. Marsh Ottawa & $.43 * * *$ & $.37 * * *$ \\
\hline 10. Temperate Forest & $.47 * * *$ & $.34 * * *$ \\
\hline
\end{tabular}

\section{Discussion}

In this research we sought to better understand why people prefer certain natural environments over others, with particular emphasis on the role of familiarity and its comparison to evolution-based theories. Our methods simultaneously compared more biomes than most prior studies, and we compared people's ratings of biomes from geographically distinct areas (Florida 
and Ontario). Results suggested a robust positive association between self-reported familiarity and the composite positive ratings of biomes, and we infer that broadly positive ratings indicate preferences for these biomes. However, some limits to the role of familiarity were also apparent. Participants' geographical proximity was often, but not ubiquitously, linked to positive evaluations of local biomes, and the role of proximity was often exceeded by the variation across biomes. For example, beaches, lakes, and mountains were preferred over tropical forests, swamps, and marshes for participants in both locations. We also explored the roles of more specific positive evaluations (e.g., safety, restoration, beauty) and seasonality (in the Canadian sample), but found few meaningful distinctions. In contrast, nature relatedness, as an individual difference measure, predicted more familiarity and positive evaluations of all the environments except beaches, perhaps because beaches were so highly preferred in general. Although our results are roughly consistent with trends in past research, they do not provide full support for any of the existing preference drivers which seek to explain biome preferences.

Similar to a number of existing studies, savannah preference theory was not supported by this study, as a number of biome types were preferred over the North American cultivated park biome type (e.g., Han, 2007; Hartmann \& Apaolaza-Ibáñez, 2010). The innate preference hypothesis was not able to be evaluated in this study, as we measured participants' hometown, but not hometown natural environment types, and a child sample was not included. Results were very similar when restricting analyses to participants based on near hometown locations, casting some doubt on the necessity of early experience, but more sophisticated assessment of childhood experiences could reveal different results. Moreover, in regards to both innate preference and familiarity preference drivers, the finding that several biome types were preferred irrespective of familiarity, and that some unfamiliar biome types, such as beach and mountains for Ottawans 
and mountains, lakes, temperate forests and rivers for Fort Lauderdaleans, suggest that neither preference driver can be used to determine people's preferences in absolute terms. Biome type preferences are more nuanced. It may be that some biome types are generally universally preferred across cultures, locations, and climates, as beaches, lakes, mountains, and rivers have generally been highly preferred in previous studies (Echeverri et al., 2017; Hartmann \& Apaolaza-Ibáñez, 2010; Jones et al., 1976; White et al., 2010; Wyles et al., 2017). Future research should investigate preferences for these biome types across diverse cultures, locations, and climates, to determine the extent of the positive valuation of these biome types, as well as to provide greater understanding of people's biome type drivers.

Given the broad support for the relatively scantly researched mountain and beach biome types, regardless of hometown, investigations into subsets of these general biome types, and other less researched biome types (eg., volcanic, cavernous, arctic, and meadow biome types), may help determine people's preference drivers, and will help determine the relative preference of various biome types and sub-biome types and qualities. Water bodies other than lakes and swamps tend to be lacking, particularly waterfalls and moving water bodies within different climate regions. Moreover, since the majority of major cities and populations are located within tropical ecosystems, combined with the general support for familiarity preference drivers found in this and other studies, tropical biome type preferences are important to evaluate. Yet tropical waterscapes beyond beaches and swamps, and landscapes beyond tropical forests, such as tropical waterfalls, bays, lakes, cloud forests, volcanoes, and streams, have not yet been studied, to the best of the authors' knowledge. While the tropical forests and swamps in this study were not highly preferred, hybrid forest with water body biome types are generally more preferred than stand-alone forest biome types, suggesting tropical forests combined with waterscapes could 
be more preferred (e.g., Hartmann \& Apaolaza-Ibáñez, 2010; Jones et al., 1976; White et al., 2013). Moreover, ecotones (i.e., transition areas where multiple biomes integrate) have received relatively little attention, but studies that have evaluated ecotones suggest they can be highly preferred, depending on the type, thereby meriting further research (Harding, 2006; Hartmann \& Apaolaza-Ibáñez, 2010; White et al., 2013).

Another approach would be to study the low-level visual features (e.g., edge density, color diversity, hue) across and within biome types as drivers of preferences (e.g., Kardan et al., 2015), which might suggest, for example, that designers incorporate color diversity, regardless of biome type. The relative preference for vibrant colors within different biome types might also be explored (e.g. temperate forests with vibrant flower understories, flower dominated meadows, variously colored vegetation and rock-based mountains, flower covered rivers, marshes, and shorelines), given existing findings of preferences for floral and other vibrant color biome subtypes (e.g., Lindemann-Matthies \& Bose, 2007).

Future research should seek to clarify the impact of activity type on people's environment type preferences, as there is evidence it has a substantial impact. For instance, Mangone (2017) found knowledge workers' relative preference for different natural and semi-natural environments (eg., dense forest, forest amphitheater) varied depending on activity type, and that different natural environments were perceived to have different scales of naturalness and fascination stimuli, the key characteristic of restorative environments. While there is currently a dearth of research on children natural environment type preferences, existing studies indicate wild natural environments are more preferred over cultivated landscapes and built playgrounds, at least in part because they are more conducive for more creative and diverse activities (eg., Bagot et al., 2015; Laaksoharju et al., 2012; Southon et al., 2017). Similarly, in the limited 
existing studies on recreation environment preferences, environment types that are more natural tend to be more preferred (Burgess et al., 1988; Giles-Corti et al., 2005). While rarely evaluated, natural environments were found to be more preferred for visiting than living next to in Lyons (1983). Despite these promising findings, the influence of activity types on environment type preferences remains substantially understudied.

The positive correlations in our study among ratings of publicness, positivity, and familiarity are also interesting to consider, though other research suggests that these associations could depend on the particular activity, rather than showing omnipresent desire for public spaces (eg., Giancarlo Mangone, Capaldi, van Allen, \& Luscuere, 2017). These studies suggest that people's degree of privacy preference for different activities varies, and that different environment types and spaces are perceived to offer different degrees of privacy. Identifying both privacy preferences for different activities, and the relative value of different natural environment types to foster the desired degree of privacy, would aid designers in designing landscape that facilitate different activities that cater to people's desired degree of privacy. This could increase the use and valuation of these spaces. It is also worth noting that public ratings were substantially less correlated with other attractive features in our 'positivity composite', i.e., so much so that we did not combine it with other ratings. This may signal a less robust link, and one that might not be observed with other methods. For example, all ratings in our study were scored in the same direction; therefore, response biases (e.g., acquiescence bias) could generate or inflate positive correlations among features such as between positivity and publicness or familiarity (more on this just below).

Other methodological choices resulted in strengths and limitations that warrant further comment. We opted to assess ten distinct biomes, and with four images of each. Although there 
were certainly more biomes we might have assessed, ten allowed for broader comparisons than the majority of previous studies. Additionally, with four exemplars of each, we sought to avoid the limitations of narrow stimulus sampling (i.e., trying to generalize to the broader biome class from a single example, see Wells \& Windschitl,1999), though more examples would likely provide more broadly applicable mean ratings. In a similar vein, although we assessed two geographically distinct samples, our participants are clearly limited by the demographics and experiences of this subset of North American university students. Asking more diverse people and age groups about these biomes would be unequivocal improvements to this (or a similar future) study. However, asking about more individual images in a single study may not yield more useful results, depending on other method choices.

Our data does not make fine distinctions among the many positive features we assessed because participants' ratings correlated so highly across them. For example, Table 1 shows that the degree to which people liked the temperate forest images correlated with ratings of 10 other positive features $>.75$. One could interpret such correlations to suggest that people cannot or do not make distinctions between how preferred, restorative, how safe, how much they want to live in a place, etc. However, we suspect that the context of our study likely discouraged such distinctions, whereas other methods/studies may well have uncovered more fine-grained distinctions (e.g., Mangone et al., 2017). More specifically, we averaged across four examples of each biome, and this will begin to cancel out idiosyncrasies of individual images in favor of a more averaged view of the category. Such averages likely pull for a general positivity, rather than quirky combinations that specific locations have (e.g., from a particular fascinating but dangerous forest, to averaged ratings of people who see forests as generally safe and fascinating), or, in other words, between-person variation rather than image-based, within-person variation. 
With that said, consistent differences across biomes could (and did) still emerge. In addition, our participants made 520 ratings of images, and the sheer volume, coupled with the online administration, may have produced fatigue or boredom and encouraged speed and heuristics over reflection and nuance. The images were also devoid of context, which might have provided more basis for distinctions. Distance from an urban center, or imagining the biome for work vs. play vs. residence, may well change perceptions of biomes' characteristics (Balling \& Falk, 1982; Mangone et al., 2017).

Future studies could pursue greater breadth (more biomes) or depth (many distinct features), but probably not both. That is, if asking about many different images, it seems unlikely that future samples would draw sharp distinctions between different positive features. It may be sufficient to ask only one question about overall positivity in such broad studies, and then participants might tolerate rating more examples of more biomes (e.g., ratings of hundreds of images). Such an approach could also allow for manipulations within each biome (e.g., with buildings present or absent). In contrast, focusing on a smaller set of key images/biomes, perhaps with instructions to mentally immerse oneself in the context, or using virtual reality technology to impose such immersion, may well allow for finer distinctions between restoration, safety, or a place to reside or visit. A hybrid approach might ask participants to view a series of images (e.g., 15 swamps) and to mentally aggregate these images into ratings of the overall category. Such an approach would require fewer ratings; yet it would make no distinctions among individual images and would make obvious the grouping in researchers' minds (by biome). In sum, these method choices have tradeoffs. This particular study allowed comparisons across many biomes, but without nuance among different positive features. This does not mean that such distinctions are not important, but it did allow us to rank many biomes on a single index of positivity. 
There are reasons to be cautious about some other null distinctions in our data. We compared two Ottawa samples, in fall and winter, and found no statistically significant differences by season. Although these analyses included many people, it is possible that a small season effect could exist and studies that compared the same people across multiple seasons (i.e., within-person design) would be an even more statistically powerful design. Additionally, many other possible combinations of season, location, and biome remain untested and could be explored in other studies. On the other hand, weather effects on other global ratings, such as life satisfaction, tend to be very small or non-existent (Lucas \& Lawless, 2013), and perhaps more likely to come to mind than they are actually important (Schkade \& Kahneman, 1998). In addition, we based our analyses on where participants currently lived (Ottawa or Fort Lauderdale) and found little difference when we excluded people who grew up more than 100 $\mathrm{km}$ away from that location. Said another way, current location seemed to matter, whereas having a more distant childhood location did not (see online supplement). Still, our study was not designed in a way that strongly assessed childhood experiences; we do not know if more distant childhood locations were similar or different to current locations. Future work could ask about the biomes typical of childhood locations, or find samples who have migrated across distinct landscapes to explore this issue more carefully.

Cultivated landscapes are currently much more prevalent in urban environments and existing design guidelines and regulations (Mangone, 2018; Tabrizian et al., 2018), despite existing preference studies, and this study, demonstrating a greater preference for, and benefits that can be derived from, natural environment types (eg., Hartmann \& Apaolaza-Ibáñez, 2010; Hoyle et al., 2017; Mangone et al., 2017; Nordh \& Østby, 2013). Urban and landscape design teams lack guidance on the relative preference and benefits of different natural environment 
types, particularly in relation to the diverse contexts their projects are situated within. Deepening our understanding of natural environment type preferences, drivers, and benefits will help planners, landscape architects, municipalities, developers, and communities to incorporate landscapes and natural environment restoration and conservation projects into communities in ways that maximize the benefits natural environments confer to all stakeholders, and the desirability and livability of communities.

If the benefits of natural environments, including resident valuation and preferences for natural environments, is made clearer to stakeholders and beneficiaries, existing natural environments will be more likely to be preserved or incorporated into master plan designs and community regeneration projects. For landscapes within disturbed land and natural environments adjacent to urban areas, landscape designers, planners, and architects will have more design guidance and justification for nature integration, preservation, and restoration integrated designs to clients and communities. For instance, wet and nutrient poor natural environments are often the most disturbed and removed natural habitat type in urban areas, yet they are also vital for diverse species and ecosystem services (Kowarik, 2011). Developing a deeper understanding of the types of wet and low nutrient habitats that people most prefer within a given context, and their socioeconomic value and relative preference to other local and potential natural environment types, will aid project stakeholders and beneficiaries in improving the quality of their community and help promote the preservation, restoration, and development of natural environments within and around urban areas.

Understanding the relative value of different natural environments will also help improve the desirability of compact development, by ensuring communities have access to highly valued nature space, which, along with walkability, has been found to be a key driver for people's 
compact development valuations and preferences (Morrow-Jones et al., 2006), and offer diverse benefits, including improving resident physical, social, and mental health (eg., Cox et al., 2017; Mangone, 2018). High value nature access can be increased by allowing for the identification and clarification of the benefits of local natural environments and areas that could effectively function as green wedges and belts, and identifying which nature areas green corridors should be connected with, in order to maximize nature visits and accessibility (Tyrväinen et al., 2007;

Žlender \& Ward Thompson, 2017). Compact development, in turn, reduces urban sprawl, which is one of the largest drivers of direct habitat loss globally (Noss, 2000; Vackár, 2012; Venter et al., 2016), and offers additional diverse socioeconomic benefits, including rural economic development, increased job opportunities, free time, and improved well-being (eg., Ewing et al., 2016; Sallis et al., 2012).

Further research will also create the knowledge needed to craft the general principles (theories) that will succinctly convey this essential guidance to practitioners, and answer deep questions about why (and when) humans are drawn to natural environments.

\section{References}

Appleton, J. (1975). The Experience of Landscape. John Wiley \& Sons.

Bagot, K. L., Allen, F. C. L., \& Toukhsati, S. (2015). Perceived restorativeness of children's school playground environments: Nature, playground features and play period experiences. Journal of Environmental Psychology, 41, 1-9. https://doi.org/http://dx.doi.org/10.1016/j.jenvp.2014.11.005

Balling, J., \& Falk, J. (1982). Development of Visual Preference for Natural Environments. 
Environment and Behavior, 14(1), 5-28.

Barrett, H. C. (2012). A hierarchical model of the evolution of human brain specializations. Proceedings of the National Academy of Sciences, 109(Supplement 1), 10733 LP - 10740. https://doi.org/10.1073/pnas.1201898109

Boyd, F., White, M. P., Bell, S. L., \& Burt, J. (2018). Who doesn't visit natural environments for recreation and why: A population representative analysis of spatial, individual and temporal factors among adults in England. Landscape and Urban Planning, 175, 102-113. https://doi.org/10.1016/j.landurbplan.2018.03.016

Burgess, J., Harrison, C. M., \& Limb, M. (1988). People, Parks and the Urban Green: A Study of Popular Meanings and Values for Open Spaces in the City. Urban Studies, 25(6), 455-473. https://doi.org/10.1080/00420988820080631

Cox, D. T. C., Shanahan, D. F., Hudson, H. L., Fuller, R. A., Anderson, K., Hancock, S., \& Gaston, K. J. (2017). Doses of nearby nature simultaneously associated with multiple health benefits. International Journal of Environmental Research and Public Health, 14(2), 172. https://doi.org/10.3390/ijerph14020172

Dopko, R. L., Zelenski, J. M., \& Nisbet, E. K. (2014). Nature salience increases judgments of environmental satisfaction. Ecopsychology, 6(4), 207-217.

Echeverri, A., Callahan, M. M., Chan, K. M. A., Satterfield, T., \& Zhao, J. (2017). Explicit not implicit preferences predict conservation intentions for endangered species and biomes. PloS One. https://doi.org/10.1371/journal.pone.0170973

Ewing, R., Hamidi, S., Grace, J. B., \& Wei, Y. D. (2016). Does urban sprawl hold down upward 
mobility? Landscape and Urban Planning, 148, 80-88.

https://doi.org/10.1016/j.landurbplan.2015.11.012

Giles-Corti, B., Broomhall, M. H., Knuiman, M., Collins, C., Douglas, K., Ng, K., Lange, A., \& Donovan, R. J. (2005). Increasing walking: How important is distance to, attractiveness, and size of public open space? American Journal of Preventive Medicine, 28(2), 169-176. https://doi.org/10.1016/j.amepre.2004.10.018

Grahn, P. (1991). Landscapes in our minds: people's choice of recreative places in towns. Landscape Research, 16(1), 11-19. https://doi.org/10.1080/01426399108706326

Gundersen, V., Skår, M., O’Brien, L., Wold, L. C., \& Follo, G. (2016). Children and nearby nature: A nationwide parental survey from Norway. Urban Forestry \& Urban Greening, 17, 116-125. https://doi.org/10.1016/J.UFUG.2016.04.002

Hammitt, W. E. (1980). Managing bog environments for recreational experiences. Environmental Management, 4(5), 425-431. https://doi.org/10.1007/BF01869653

Han, K.-T. (2007). Responses to Six Major Terrestrial Biomes in Terms of Scenic Beauty, Preference, and Restorativeness. Environment and Behavior, 39(4), 529-556. https://doi.org/10.1177/0013916506292016

Harding, S. (2006). Animate earth : science, intuition and Gaia. Chelsea Green Pub. Co.

Hartig, T., Korpela, K., Evans, G. W., \& Garling, T. (1997). A measure of restorative quality in environments. Scandinavian Housing and Planning Research, 14, 175-194.

Hartig, Terry, \& Staats, H. (2006). Linking preference for environments with their restorative quality. Landscape Research to Landscape Planning : Aspects of Integration, Education 
and Application, 279-292.

Hartmann, P., \& Apaolaza-Ibáñez, V. (2010). Beyond savanna: An evolutionary and environmental psychology approach to behavioral effects of nature scenery in green advertising. Journal of Environmental Psychology, 30(1), 119-128. https://doi.org/http://dx.doi.org/10.1016/j.jenvp.2009.10.001

Herzog, T. R. (1985). A cognitive analysis of preference for waterscapes. Journal of Environmental Psychology, 5(3), 225-241. https://doi.org/http://dx.doi.org/10.1016/S02724944(85)80024-4

Herzog, T. R., Herbert, E. J., Kaplan, R., \& Crooks, C. L. (2000). Cultural and Developmental Comparisons of Landscape Perceptions and Preferences. Environment and Behavior, 32(3), $323-346$.

Hoyle, H., Hitchmough, J., \& Jorgensen, A. (2017). All about the 'wow factor'? The relationships between aesthetics, restorative effect and perceived biodiversity in designed urban planting. Landscape and Urban Planning, 164, 109-123. https://doi.org/10.1016/J.LANDURBPLAN.2017.03.011

Hull, B. R., \& Harvey, A. (1989). Explaining the Emotion People Experience in Suburban Parks. Environment and Behavior, 21(3), 323-345.

Jones, G. R., Ady, J., \& Gray, B. A. (1976). Scenic and recreational highway study for the state of Washington. Landscape Planning, 3(3), 151-302. https://doi.org/http://dx.doi.org/10.1016/0304-3924(76)90071-X

Kaplan, R., \& Herbert, E. J. (1987). Cultural and sub-cultural comparisons in preferences for 
natural settings. Landscape and Urban Planning, 14, 281-293.

Kaplan, S. (1995). The restorative benefits of nature: Toward an integrative framework. Journal of Environmental Psychology, 15(3), 169-182. https://doi.org/Doi: 10.1016/02724944(95)90001-2

Kardan, O., Demiralp, E., Hout, M. C., Hunter, M. R., Karimi, H., Hanayik, T., Yourganov, G., Jonides, J., \& Berman, M. G. (2015). Is the preference of natural versus man-made scenes driven by bottom-up processing of the visual features of nature? Frontiers in Psychology, 6, 471. https://doi.org/10.3389/fpsyg.2015.00471

Knight, C., \& Haslam, S. A. (2010). The relative merits of lean, enriched, and empowered offices: an experimental examination of the impact of workspace management strategies on well-being and productivity. Journal of Experimental Psychology, 16(2), 158-172.

Korpela, K. M., Ylén, M., Tyrväinen, L., \& Silvennoinen, H. (2010). Favorite green, waterside and urban environments, restorative experiences and perceived health in Finland. Health Promotion International, 25(2), 200-209. https://doi.org/10.1093/heapro/daq007

Kowarik, I. (2011). Novel urban ecosystems, biodiversity, and conservation. Environmental Pollution, 159(8-9), 1974-1983. https://doi.org/10.1016/j.envpol.2011.02.022

Kuller, R. (1972). A semantic model for describing perceived environment. National Swedish Institute for Building Research, $D(12)$.

Laaksoharju, T., \& Rappe, E. (2017). Trees as affordances for connectedness to place-a framework to facilitate children's relationship with nature. Urban Forestry \& Urban Greening, 28, 150-159. https://doi.org/10.1016/J.UFUG.2017.10.004 
Laaksoharju, T., Rappe, E., \& Kaivola, T. (2012). Garden affordances for social learning, play, and for building nature-child relationship. Urban Forestry \& Urban Greening, 11(2), 195203. https://doi.org/10.1016/J.UFUG.2012.01.003

Lee, M. S. (1979). Landscape preference assessment of Louisiana river landscapes : a methodological study. In Our Landscape : A conference on applied techniques for analysis and management of the visual resource (pp. 572-580). U.S. Department of Agriculture.

Lin, B. B., Fuller, R. A., Bush, R., Gaston, K. J., \& Shanahan, D. F. (2014). Opportunity or orientation? Who uses urban parks and why. PloS One, 9(1), e87422.

Lindemann-Matthies, P., \& Bose, E. (2007). Species richness, structural diversity and species composition in meadows created by visitors of a botanical garden in Switzerland. Landscape and Urban Planning, 79(3-4), 298-307. https://doi.org/http://dx.doi.org/10.1016/j.landurbplan.2006.03.007

Lucas, R. E., \& Lawless, N. M. (2013). Does life seem better on a sunny day? Examining the association between daily weather conditions and life satisfaction judgments. Journal of Personality and Social Psychology, 104(5), 872-884.

Lyons, E. (1983). Demographic Correlates of Landscape Preference. Environment and Behavior, 15(4), 487-511. https://doi.org/10.1177/0013916583154005

Mangone, G. (2018). Exploring urban design strategies that maximize the benefits of urban nature for children's well-being. Ecopsychology, 10(4), 216-227.

Mangone, G., Capaldi, C. A., van Allen, Z. M., \& Luscuere, P. G. (2017). Bringing nature to work: Preferences and perceptions of constructed indoor and natural outdoor workspaces. 
Urban Forestry \& Urban Greening, 23, 1-12. https://doi.org/10.1016/j.ufug.2017.02.009

Martens, D., Gutscher, H., \& Bauer, N. (2011). Walking in "wild" and "tended" urban forests: The impact on psychological well-being. Journal of Environmental Psychology, 31, 36-44. https://doi.org/10.1016/j.jenvp.2010.11.001

Morrow-Jones, H., Irwin, E., \& Roe, B. (2006). Consumer preference for neotraditional neighborhood characteristics. Housing Policy Debate, 34(2).

Moura, J. M. B., Ferreira Júnior, W. S., Silva, T. C., \& Albuquerque, U. P. (2018). The Influence of the Evolutionary Past on the Mind: An Analysis of the Preference for Landscapes in the Human Species . In Frontiers in Psychology (Vol. 9, p. 2485). https://www.frontiersin.org/article/10.3389/fpsyg.2018.02485

Nisbet, E. K., Zelenski, J. M., \& Murphy, S. A. (2011). Happiness is in our Nature: Exploring Nature Relatedness as a Contributor to Subjective Well-Being. Journal of Happiness Studies, 12(2), 303-322. https://doi.org/10.1007/s10902-010-9197-7

Nordh, H., \& Østby, K. (2013). Pocket parks for people - A study of park design and use. Urban Forestry \& Urban Greening, 12(1), 12-17. https://doi.org/10.1016/J.UFUG.2012.11.003

Noss, R. F. (2000). High-risk ecosystems as foci for considering biodiversity and ecological integrity in ecological risk assessments. Environmental Science \& Policy, 3(6), 321-332. https://doi.org/Doi: 10.1016/s1462-9011(00)00112-x

Odum, E. P. (1993). Ecology and our endangered life-support systems. Sinauer Associates.

Olson, D. M., Dinerstein, E., Wikramanayake, E. D., Burgess, N. D., Powell, G. V. N., Underwood, E. C., D’amico, J. A., Itoua, I., Strand, H. E., Morrison, J. C., Loucks, C. J., 
Allnutt, T. F., Ricketts, T. H., Kura, Y., Lamoreux, J. F., Wettengel, W. W., Hedao, P., \& Kassem, K. R. (2001). Terrestrial Ecoregions of the World: A New Map of Life on Earth. BioScience, 51(11), 933-938. https://doi.org/10.1641/0006-

3568(2001)051[0933:TEOTWA]2.0.CO;2

Park, B.-J., Furuya, K., Kasetani, T., Takayama, N., Kagawa, T., \& Miyazaki, Y. (2011). Relationship between psychological responses and physical environments in forest settings. Landscape and Urban Planning, 102(1), 24-32. https://doi.org/10.1016/j.landurbplan.2011.03.005

Peron, E., Berto, R., \& Purcell, T. (2002). Restorativeness, preference, and the perceived naturalness of place. Medio Ambiente y Comprotamiento Humano, 3(1), 19-34.

Purcell, T., Peron, E., \& Berto, R. (2001). Why do Preferences Differ between Scene Types? Environment and Behavior, 33(1), 93-106. https://doi.org/10.1177/00139160121972882

Sallis, J. F., Floyd, M. F., Rodríguez, D. A., \& Saelens, B. E. (2012). Role of Built Environments in Physical Activity, Obesity, and Cardiovascular Disease. Circulation, 125(5), 729-737. https://doi.org/10.1161/circulationaha.110.969022

Scardia, G., Parenti, F., Miggins, D. P., Gerdes, A., Araujo, A. G. M., \& Neves, W. A. (2019). Chronologic constraints on hominin dispersal outside Africa since $2.48 \mathrm{Ma}$ from the Zarqa Valley, Jordan. Quaternary Science Reviews, 219, 1-19. https://doi.org/https://doi.org/10.1016/j.quascirev.2019.06.007

Schkade, D. A., \& Kahneman, D. (1998). Does living in California make people happy? A focusing illusion in judgments of life satisfaction. Psychological Science, 9(5), 340-346. 
Simmons, J. P., Nelson, L. D., \& Simmonsohn, U. (2012). A 21 Word Solution. SSRN.

Southon, G. E., Jorgensen, A., Dunnett, N., Hoyle, H., \& Evans, K. L. (2017). Biodiverse perennial meadows have aesthetic value and increase residents' perceptions of site quality in urban green-space. Landscape and Urban Planning, 158, 105-118. https://doi.org/10.1016/J.LANDURBPLAN.2016.08.003

Staats, H., Kieviet, A., \& Hartig, T. (2003). Where to recover from attentional fatigue: An expectancy-value analysis of environmental preference. Journal of Environmental Psychology, 23(2), 147-157. https://doi.org/Doi: 10.1016/s0272-4944(02)00112-3

Steg, L., \& Vlek, C. (2009). Encouraging pro-environmental behaviour: An integrative review and research agenda. Journal of Environmental Psychology, 29(3), 309-317. https://doi.org/http://dx.doi.org/10.1016/j.jenvp.2008.10.004

Stern, M. J., Powell, R. B., \& Ardoin, N. M. (2008). What difference does it make? Assessing the outcomes from participation in a residential enviornmental education program. Journal of Environmental Education, 39, 31-43.

Tabrizian, P., Baran, P. K., Smith, W. R., \& Meentemeyer, R. K. (2018). Exploring perceived restoration potential of urban green enclosure through immersive virtual environments. Journal of Environmental Psychology, 55, 99-109. https://doi.org/10.1016/J.JENVP.2018.01.001

Tenngart Ivarsson, C., \& Hagerhall, C. M. (2008). The perceived restorativeness of gardens Assessing the restorativeness of a mixed built and natural scene type. Urban Forestry \& Urban Greening, 7(2), 107-118. https://doi.org/http://dx.doi.org/10.1016/j.ufug.2008.01.001 
Townsend, J. B., \& Barton, S. (2018). The impact of ancient tree form on modern landscape preferences. Urban Forestry \& Urban Greening, 34, 205-216.

Tyrväinen, L., Mäkinen, K., \& Schipperijn, J. (2007). Tools for mapping social values of urban woodlands and other green areas. Landscape and Urban Planning, 79(1), 5-19. https://doi.org/https://doi.org/10.1016/j.landurbplan.2006.03.003

Ulrich, R. S. (1983). Aesthetic and Affective Response to Natural Environment. In I. Altman \& J. F. Wohlwill (Eds.), Behavior and the Natural Environment (Vol. 6, pp. 85-125). Springer . https://doi.org/10.1007/978-1-4613-3539-9_4

Vackár, D. (2012). Ecological Footprint, environmental performance and biodiversity: A crossnational comparison. Ecological Indicators, 16, 40-46.

Venter, O., Sanderson, E. W., Magrach, A., Allan, J. R., Beher, J., Jones, K. R., Possingham, H. P., Laurance, W. F., Wood, P., Fekete, B. M., Levy, M. A., Watson, J. E. M., Liu, J., Costanza, R., Kareiva, P., Watts, S., McDonald, R., Boucher, T., Steffen, W., ... Olson, D. M. (2016). Sixteen years of change in the global terrestrial human footprint and implications for biodiversity conservation. Nature Communications, 7, 12558. https://doi.org/10.1038/ncomms 12558

Wells, G. L., \& Windschitl, P. D. (1999). Stimulus sampling and social psychological experimentation. Personality and Social Psychology Bulletin, 25(9), 1115-1125.

White, M. P., Pahl, S., Ashbullby, K., Herbert, S., \& Depledge, M. H. (2013). Feelings of restoration from recent nature visits. Journal of Environmental Psychology, 35(0), 40-51. https://doi.org/http://dx.doi.org/10.1016/j.jenvp.2013.04.002 
White, M. P., Smith, A., Humphryes, K., Pahl, S., Snelling, D., \& Depledge, M. (2010). Blue space: The importance of water for preference, affect, and restorativeness ratings of natural and built scenes. Journal of Environmental Psychology, 30(4), 482-493. https://doi.org/http://dx.doi.org/10.1016/j.jenvp.2010.04.004

Williams, K. J. H., \& John, C. (2002). Landscape preferences, ecological quality, and biodiversity protection. Journal of Planning Literature, 17(1), 85-168.

Wyles, K. J., White, M. P., Hattam, C., Pahl, S., King, H., \& Austen, M. (2017). Are Some Natural Environments More Psychologically Beneficial Than Others? The Importance of Type and Quality on Connectedness to Nature and Psychological Restoration. Environment and Behavior, 001391651773831. https://doi.org/10.1177/0013916517738312

Yabiku, S., Casagrande, D., \& Farley-Metzger, E. (2008). Preferences for Landscape Choice in a Southwestern Desert City. Environment and Behavior, 40(3), 382-400.

Žlender, V., \& Ward Thompson, C. (2017). Accessibility and use of peri-urban green space for inner-city dwellers: A comparative study. Landscape and Urban Planning, 165, 193-205. https://doi.org/https://doi.org/10.1016/j.landurbplan.2016.06.011 